Article

\title{
Challenges for Sustainable Water Use in the Urban Industry of Korea Based on the Global Non-Radial Directional Distance Function Model
}

\author{
Na Wang ${ }^{1, *(D)}$ and Yongrok Choi ${ }^{2, *(D)}$ \\ 1 Institute of Blue and Green Development, Shandong University, Weihai 264209, China \\ 2 Global E-governance Program, Inha University, Inharo100, Nam-gu, Incheon 402-751, Korea \\ * Correspondence: 5sunnywang@live.cn (N.W.); yrchoi@inha.ac.kr (Y.C.)
}

Received: 17 June 2019; Accepted: 9 July 2019; Published: 17 July 2019

\begin{abstract}
Since water stress and industrial water pollution pose a huge threat to South Korea's sustainable water use, it is an urgent task to assess industrial water green use efficiency (GUEIW). Based on the global non-radial directional distance function (GNDDF) model, this paper calculated GUEIW in 16 Korean local governments from 2006 to 2015 using two decomposition indicators: Economic efficiency of industrial water use (ECEIW) and environmental efficiency of industrial water use (ENEIW). The growth of GUEIW is mainly driven by ECEIW, and subsequent environmental problems are obstacles to achieving green use of Korean industrial water. The regional heterogeneity of GUEIW is so important that the downstream region outperformed the upstream region in all three indicators. The government's efforts to ensure water quality inhibits industrial development in upstream areas, where incomes are much lower than in downstream areas, and downstream industrial areas have to pay upstream industrial areas extra for water. However, regarding upstream industrial areas, low prices easily promote water waste. Because of relatively high water use costs, downstream producers are encouraged to save water. To improve the economic efficiency of industrial water use in upstream areas, advanced water technology should be developed or introduced to make full use of water resources in industrial production.
\end{abstract}

Keywords: water resource; South Korean urban industry; green use efficiency of industrial water (GUEIW); global non-radial directional distance function model (GNDDF); economic efficiency of industrial water use (ECEIW); environmental efficiency of industrial water use (ENEIW)

\section{Introduction}

\subsection{Background of the Research}

In the 20th century, oil was referred to as black gold, the "core of the world market economy," but in the 21st century, "blue gold," or water, has become an increasingly valuable resource due to population explosion, climate change, and the current world economic model [1]. Water systems are vital to human well-being and offer diverse benefits to society. Water policies have long aimed at optimal water use due to the ever-increasing demand for limited water resources in many parts of the world $[2,3]$.

However, many countries around the world still face significant challenges in managing their scarce water resources due to industrialization, urbanization, and climate change. Industrialization and urbanization, driven by population pressure, are the main factors of economic growth; meanwhile, intensive agricultural spread-out use of high pesticides has also become dominant, resulting in water shortage and degradation in many parts of the world. In addition, climate change has increased characteristics of severe spatial and temporal variations in water resources [4]. 
South Korea ("Korea") is no exception. Over the past few decades, the Korean economic growth rate has been astonishingly high [4,5]. Unfortunately, economic growth has come at the expense of the environment [6,7], indicated by water shortage and deteriorating water quality [8] which became serious problems in the 1990s [9]. Rapid economic development has led to urban, industrial, and agricultural pollution that has severely disrupted water supplies and ecosystems. Population and industrial growth have increased pressure on limited available water resources, resulting in water conflicts among stakeholders [10]. Sewage contains a large number of organic pollutants which affect the ecosystem in the form of toxicity, reduce dissolved oxygen in water, and endanger human health. Specific organic pollutants refer to organic compounds with high toxicity, strong accumulation, and delayed degradation that are listed as priority pollutants [11]. Organic pollutants have different characteristics. The hazardous substances are a minor fraction of wastewater, often measured in $\mu \mathrm{g} / \mathrm{L}$, while the less harmful organic substances may be given in hundreds or even thousands of $\mathrm{mg} / \mathrm{L}$. They are not toxic or pose a strong risk to human health but are responsible for oxygen consumption in receiving water bodies and for this reason should be reduced by treatment. The water resources management information system of the Korean government advises that the concentration of organic pollutants (BOD) needs to be kept below $10 \mathrm{mg} / \mathrm{L}$ [12]. Regarding water regulation policies, an intermediate law concerning the flow of river water was introduced in 1999, which mandates lowland water users to pay upland residents in an effort to reduce agricultural intensification (Agricultural intensification refers to a kind of agricultural operation mode in which more labor, capital, and technology are invested in a certain area of land in order to obtain more output per unit area and simultaneously reduce the labor cost per unit of product.) in the upland regions and decrease the need for more water pollution treatment facilities. However, water pollution has still occurred $[13,14]$.

More than direct regulatory policies, therefore, water prices may play an important role in determining the efficiency of resource utilization, as suggested by Kumbhakar and Bhattacharyya [15]. Specifically, relatively low prices can easily promote water waste, and relatively high prices may lead to higher production costs, thus encouraging water consumers to save water [16]. Therefore, the price should be set within a reasonable range for sustainable use of water. Uncontrolled water wastage and numerous water pollution incidents have made the problems of water shortage and degradation more serious, which has led to a huge negative impact on social and economic development [17-19]. Therefore, improving water efficiency and reducing water pollution are crucial for sustainable water use [20-23].

As for the estimation of resource efficiency, many recent studies prefer the distance function method, which simultaneously takes multiple input and output factors into account [24-29]. There are two methods for estimating the distance function: The nonparametric data envelope analysis (DEA) method and the parametric method. The DEA method was proposed by Charnes et al. [30] and has been widely applied in recent environmental and energy-related studies [31]. A major advantage of the DEA method over the parametric method is that it does not require the underlying technology to have a specific functional form [32-35].

As for the evaluation of water use efficiency in China, Hu et al. [36] developed the pioneer empirical analytic framework DEA to evaluate water use efficiency at the national level. The concept adjustment quantity they proposed was used to determine the optimal scale of water use. Liao and Dong [37] adopted a similar method to evaluate the efficiency of provincial water resources utilization. However, these studies only took economic benefits into account and may be considered only a part of a comprehensive analysis because they ignored pollutants (such as water waste and water pollution) from industrial production. Therefore, the expected output should also be considered along with the undesirable output. By utilizing this undesirable output in our model, "green use efficiency" will be achieved [38-41]. In addition, most previous studies tended to use the radial DEA method, which aims to increase the good output and reduce the bad output at the same rate. This is inconsistent with actual production activities and often leads to the same efficiency value of 1 for many evaluated observations, making it very difficult to evaluate the observed results in an appropriate manner [42]. In addition, as pointed out by Zhang et al. [32], many relevant studies have used time series data only, 
but studies on cross-sectional data can be regarded as yielding more efficient and effective evaluations over the same period. Obviously, production technology varies from year to year, and results based on production technology at the same time may not be reasonable. To overcome these spatial and dynamic issues, Zhang et al. [32] and Zhang et al. [33] proposed a global non-radial directional distance function (GNDDF) method, which increased the good output and reduced the bad output at different rates and covered all contemporary technologies during the research period.

Although there are many papers on resource utilization efficiency, to our knowledge, there is no research on the analysis of the green use efficiency of industrial water (GUEIW) in Korea. Therefore, we applied a relatively advanced GNDDF model, which included undesirable output, to calculate the GUEIW in Korea from 2006 to 2015. We further analyzed water use efficiency using the economic efficiency of industrial water use (ECEIW) and the environmental efficiency of industrial water use (ENEIW) components to illuminate the major contributing factors of GUEIW. Moreover, we calculated local government-level ECEIW and ENEIW to find out which local government is more effectively promoting the efficiency of Korean industrial water use.

\subsection{Geographic Features}

Korea is located in East Asia, south of the Korean peninsula, and is surrounded by the East Sea and Yellow (West) Sea. The country lies between $124^{\circ}$ and $132^{\circ}$ longitude and between $33^{\circ}$ and $42^{\circ}$ latitude. This geographical location has a major influence on the country's climate, which is divided into four distinct seasons and is characterized by continental and temperate monsoon climates, depending on the region [43].

The country's land area is 99,596 square kilometers, with mountainous topography covering 70 percent of the country. Most of the mountains are in the eastern part, characterized by sharp declines, while the height of the western and southern regions drops slowly. This is why four major rivers flow from the eastern mountain areas into the West Sea (see Figure 1) [43]. The Han river is $481.7 \mathrm{~km}$ long, with a catchment area of 26,018 sq km, and is the largest river in South Korea; it flows through the most populous Seoul metro area, including Incheon (the third largest city), and into the West Sea. The Naktong river (506.17 km in length), with a catchment area of $23,384 \mathrm{sq} \mathrm{km}$, is the longest river flowing into the southern sea, passing through the two metropolises of Busan (second) and Daegu (fourth), as well as several industrial cities. The Geum river, which is $394.79 \mathrm{~km}$ in length and covers $9912.15 \mathrm{sq} \mathrm{km}$, begins in the central part of the country and ends in the West Sea. The cities of Daejeon and Sejong (fifth) reside on its banks. The Yeongsan, which is $115.5 \mathrm{~km}$ in length and $3371 \mathrm{sq} \mathrm{km}$ in basin area, is a river in southwestern Korea. It passes through Gwangju (sixth) and flows into the West Sea [43].

Despite heavy rainfall, water supplies in South Korea are limited. The Organization for Economic Co-operation and Development (OECD) classifies Korea as a water-stressed country (Figure 2), for, although the concept of water stress is relatively new, access to freshwater resources has become much more difficult over time and could lead to further depletion and deterioration of available water resources. Water shortage can be caused by climate change, droughts or floods, increased pollution, increased human demand, and excessive use of water resources. A water crisis can occur when the amount of potable, uncontaminated water in an area is less than what the area needs. Shortage of water resources is caused by two converging phenomena: The ever-increasing fresh water use and the exhaustion of available fresh water resources. Water stress can be the result of two mechanisms: Material (absolute) water stress and economic water stress. Material water stress is the result of water resources being naturally inadequate in meeting regional needs, while economic water stress is the result of mismanagement of adequate available water resources (OECD Environmental Outlook to 2050). 


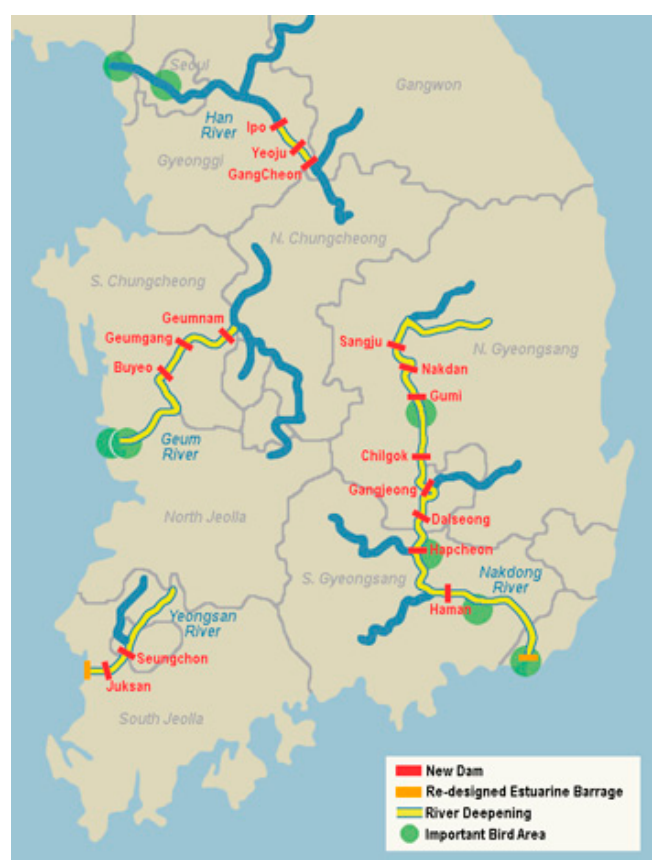

Figure 1. The four major river basins in South Korea.

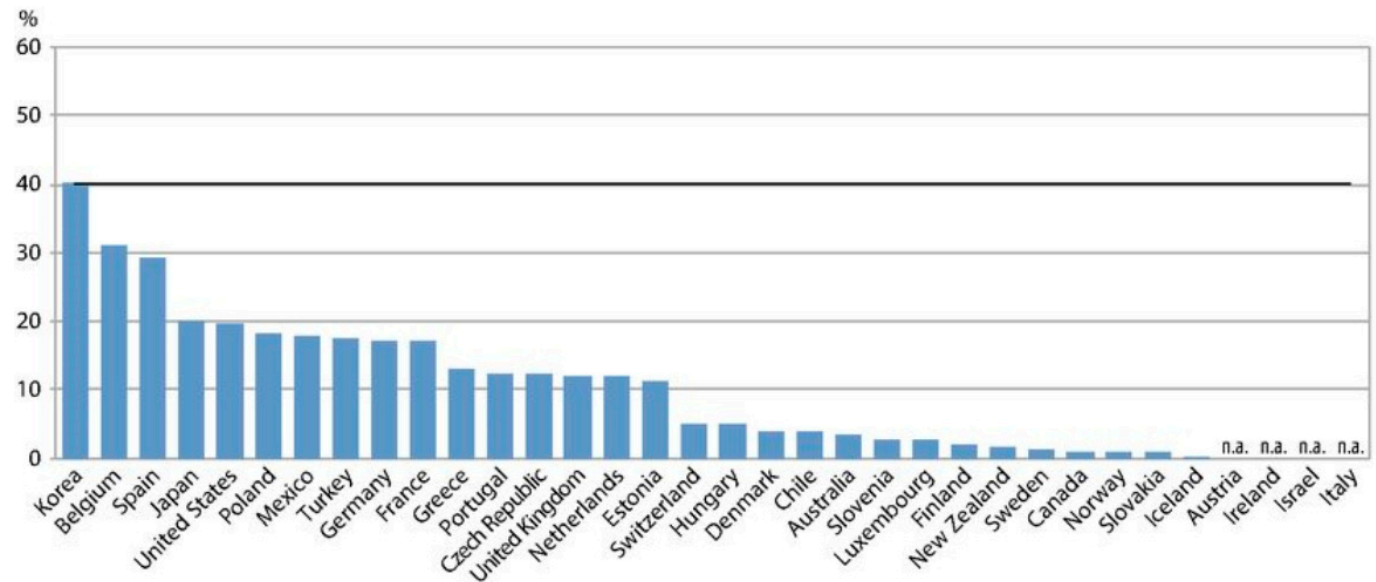

Figure 2. Water stress in Organization for Economic Co-operation and Development (OECD) countries. Note: Water stress levels: Below $10 \%=$ no stress; $10 \%-20 \%=$ low stress; $20 \%-40 \%=$ medium stress; above $40 \%$ : Severe stress.

As shown in Figure 2, compared with other OECD countries, Korea is coming close to facing a water crisis. As of 2015, Korea had used up to 33 percent of its total available water, putting the country's water balance at risk. Korea's total water resources amounted to 132.3 billion $\mathrm{m}^{3}$ in 2014, as shown in Figure 3. However, available water resources are estimated to be slightly more than half (76 billion $\mathrm{m}^{3}$, or $57 \%$ ). During the rainy season between June and September, 42.5 percent of water ( 56.3 billion $\mathrm{m}^{3}$ ) was discharged. In particular, heavy rain brought by summer monsoons and typhoons resulted in flooding in the downriver areas of the four major river basins (see Figure 3). Due to steep mountain slopes and covered soils, the surface runoff is fast and half of it goes directly into the Sea. Furthermore, almost half of the precipitation is lost due to evaporation and transpiration [44]. 


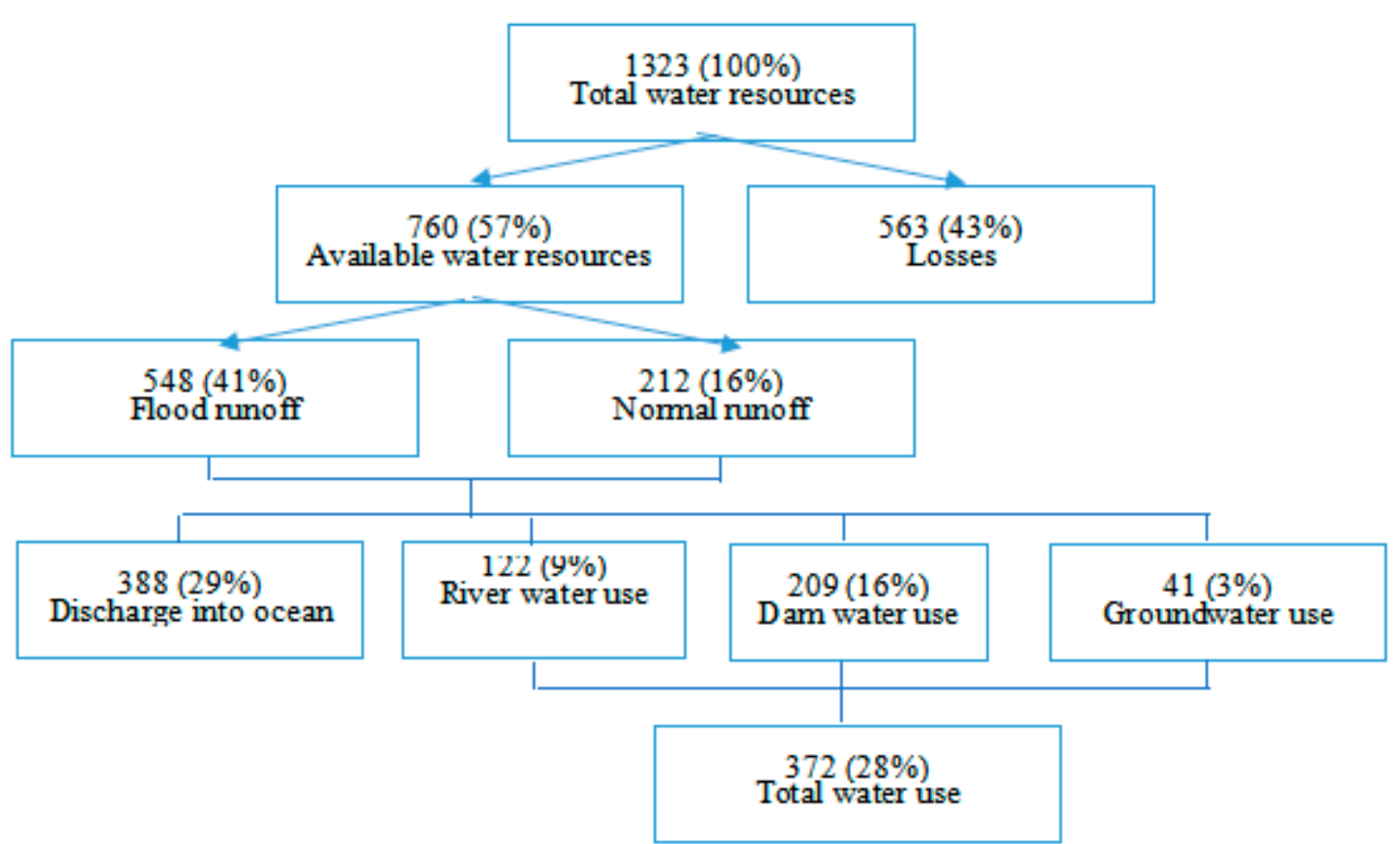

Figure 3. Distribution of water resources in South Korea, 100 million $\mathrm{m}^{3} /$ year. Note: Flood runoff is measured between June and September. Source: MoLIT (2017), The 4th Long-term Comprehensive Plan of Water Resources (2001-2020), 3rd revision.

Moreover, the proportion of water utility bills that covers production costs is far lower than total costs, with a 0.7 per cent decrease per year on average, from 84.4 percent in 2007 to 77.5 percent in 2015 (see Table 1). This continuously increasing disparity between the production costs of drinkable water and the price for which it is supplied has magnified the mismatch between water demand and supply. According to Kim [13], Korea's per capita daily water consumption of 395 liters is the highest among the 29 member nations of the OECD. The amount stands at 197.5 liters in France, 197.5 liters in Germany, and 158 liters in Denmark. Korea's low-priced water bills are likely to lead to this overuse. Therefore, in order to delineate the sustainable performance of this water policy, we will evaluate the quantitative and qualitative efficiency of water in the following section.

Table 1. Water tariff over 2007-2015.

\begin{tabular}{cccccccccc}
\hline & $\mathbf{2 0 0 7}$ & $\mathbf{2 0 0 8}$ & $\mathbf{2 0 0 9}$ & $\mathbf{2 0 1 0}$ & $\mathbf{2 0 1 1}$ & $\mathbf{2 0 1 2}$ & $\mathbf{2 0 1 3}$ & $\mathbf{2 0 1 4}$ & $\mathbf{2 0 1 5}$ \\
\hline $\begin{array}{c}\text { Public water price } \\
\left(\text { won } / \mathrm{m}^{3}\right)\end{array}$ & 603.9 & 609.3 & 609.9 & 610.2 & 619.3 & 649.1 & 660.4 & 666.9 & 683.4 \\
\hline $\begin{array}{c}\text { Production costs } \\
\left(\text { won } / \mathrm{m}^{3}\right)\end{array}$ & 715.4 & 730.7 & 761.6 & 777.2 & 813.4 & 814.7 & 849.3 & 876.5 & 881.7 \\
\hline $\begin{array}{c}\text { Cost coverage ratio } \\
(\%)\end{array}$ & 84.4 & 83.4 & 80.1 & 78.5 & 76.1 & 79.7 & 77.8 & 76.1 & 77.5 \\
\hline \multicolumn{2}{c}{ Source: Ministry of the Interior and Safety, https://www.mois.go.kr/. } & & \\
\hline
\end{tabular}

\section{Methodology}

In this section, the global non-radial directional distance function (GNDDF) is presented to evaluate water stress in terms of its efficiency. This model shows how to estimate the green use efficiency of industrial water (GUEIW), the "economic" efficiency of industrial water (ECEIW), and the "environmental" efficiency of industrial water (ENEIW). 


\subsection{GNDDF (Global Non-Radial Directional Distance Function)}

Chambers et al. [30] first introduced the traditional directional distance function (DDF). After Chung et al. [45] extended this approach to evaluate environmental efficiency, DDF became a widely accepted approach to resource and environmental efficiency assessment. As shown in Equation (1), the conventional radial directional distance function approach always assumes that all inputs and outputs are introduced at the same proportionate rate, which does not conform to real production activities. Moreover, this radial DDF approach may overestimate efficiency due to non-zero slacks existing in inputs or outputs $[46,47]$. To overcome these problems, this paper utilized a non-radial DDF approach, which is widely used in research on resource efficiency evaluations [48], as shown in Equation (2)

$$
\begin{gathered}
\vec{D}^{(x, y, b ; g)=\sup \{\beta:((x, y, b)+g \times \beta) \in T\}} \\
\vec{D}^{(x, y, b ; g)=\sup \left\{W^{T} \beta:((x, y, b)+g \times \operatorname{diag}(\beta)) \in T\right\}},
\end{gathered}
$$

where $W^{T}=(x, y, b)^{T}$ denotes a normalized weight vector with respect to inputs and outputs, $g=\left(-g_{x}, g_{y},-g_{b}\right)$ is an explicit directional vector, and $\beta=\left(\beta_{x}, \beta_{y}, \beta_{b}\right)^{T} \geq 0$ represents the vector of scaling factors. Thus, input and output may have different adjustment ratios, conforming to real production activities. The symbol diag denotes diagonal matrices and the environmental technology possibility set.

In this paper, let us assume that there are $\mathrm{N}$ local governments being evaluated. Each local government has inputs $(\mathrm{x})$ to produce desirable outputs $(\mathrm{y})$ and undesirable outputs $(\mathrm{b})$. The regulated environmental technology $T_{1}$ for $\mathrm{N}$ decision making units (DMUs) can be expressed as follows:

$$
\begin{aligned}
& T_{1}(x)=\{(x, y, b) \mid x \quad \text { can produce }(y, b):\} \\
& \text { s.t. }\left\{\begin{array}{l}
\sum_{n=1}^{N} z_{n} x_{n} \leq x \\
\sum_{n=1}^{N} \lambda_{n} y_{n} \geq y, \\
\sum_{n=1}^{N} \lambda_{n} b_{n}=b \\
\sum_{n=1}^{N} \lambda_{n}=1, \\
\lambda_{n}>0, n=1, \ldots, N,
\end{array}\right.
\end{aligned}
$$

where $T_{1}(x)$ satisfies the production function theory, implying that limited inputs can produce limited outputs only. Inactivity is assumed as well, implying that there is no production for no undesirable outputs [49]. In addition, we imposed a weak disposability hypothesis on $T_{1}(x)$, implying that the undesirable output cannot be reduced freely. Considering the production technical change during the experimental period, we applied a function that imposed the constraints $\sum_{n=1}^{N} \lambda_{n}=1$ into variable returns to scale (VRS). Because the value is estimated based on the benchmark technology of the same period, the technology is obviously different over the years. The values over different years cannot be compared with each other; therefore, we utilized a global technology benchmark to include all of the contemporary technologies over the research period. Global technology integration, as proposed by 
Pastor [50], is denoted by $T_{G}=T_{1} \cup T_{2} \cup \ldots \cup T_{N}$, and the global benchmark technology possibility set $\mathrm{T}_{2}(\mathrm{x})$ can be defined as follows:

$$
\begin{aligned}
& G T_{2(x)}=\{(x, y, b) x \text { can produce }(y, b)\} \\
& \text { s.t. }\left\{\begin{array}{l}
\sum_{t=1}^{T} \sum_{n=1}^{N} x_{n}^{t} \lambda_{n}^{t} \leq x \\
\sum_{t=1}^{T} \sum_{n=1}^{N} y_{n}^{t} \lambda_{n}^{t}=y \\
\sum_{t=1}^{T} \sum_{n=1}^{N} b_{n}^{t} \lambda_{n}^{t}=b
\end{array}\right. \\
& \lambda_{n}>0, n=1, \ldots, N, t=1,2, \ldots, T
\end{aligned}
$$

In this research, in accordance with previous research and data availability, input variables mainly included three indicators: Industrial water use (WA), industrial labor force (L), and industrial capital (K), referring to the water amount used for industrial production, the strength of the labor force in the industrial sector, and annual net industrial fixed assets, respectively. The desirable output was industrial GDP $(Y)$, while the undesirable output was the two major water stress factors in industries: Water waste and organic pollution (OP). In order to eliminate the dilution effect of industrial labor and industrial capital, we removed it from the objective function and constrained it with the "ceteris paribus" condition. Therefore, we can calculate the GUEIW through the GNDDF model as follows.

$$
\begin{aligned}
& \vec{D}=\max w_{I W} \beta_{I W}+w_{Y} \beta_{Y}+w_{W W} \beta_{W W}+w_{O P} \beta_{O P} \\
& \text { s.t. }\left\{\begin{array}{l}
\sum_{t=1}^{T} \sum_{n_{h}=1}^{N} \lambda_{n}^{t} I W_{n} \leq\left(1-\beta_{I W}\right) I W_{o}, \sum_{t=1}^{T} \sum_{n=1}^{N} \lambda_{n}^{t} L_{n} \leq L_{o}, \sum_{t=1}^{T} \sum_{n=1}^{N} \lambda_{n}^{t} K_{n} \leq K_{o}, \\
\sum_{t=1}^{T} \sum_{n=1}^{N} \lambda_{n}^{t} Y_{n} \geq\left(1+\beta_{Y}\right) Y_{o}, \\
\sum_{t=1}^{T} \sum_{n=1}^{N} \lambda_{n}^{t} W W_{n}=\left(1-\beta_{W W}\right) W W_{o}, \sum_{t=1}^{T} \sum_{n=1}^{N} \lambda_{n}^{t} O P_{n}=\left(1+\beta_{O P}\right) O P_{o}, \\
\beta_{I W} \geq 0, \beta_{Y} \geq 0, \beta_{W W} \geq 0, \beta_{O P} \geq 0,
\end{array}\right. \\
& n=1, \ldots, N ; t=1,2, \ldots, T ; \lambda_{n}^{t} \geq 0, \sum_{n=1}^{N} \lambda_{n}^{t}=1
\end{aligned}
$$

where subscript 0 refers to the evaluation of the local government. $\beta_{I W}$ is the input adjustment ratio of industrial water, $\beta_{Y}$ is the adjustment radio of desirable output of industrial GDP's, and $\beta_{W W}$ and $\beta_{O P}$ are the adjustment ratios of undesirable outputs of industrial water waste and organic pollutants. Subscript $\mathrm{n}$ refers to the number of local governments in the sample; superscript $\mathrm{t}$ is the year. When $\beta$ is zero, it means the local government is located on the production frontier.

\subsection{GUEIW (Green Use Efficiency of Industrial Water)}

In accordance with Wang et al. [51], we set the weight vector as $(1 / 3,1 / 3,1 / 6,1 / 6)$ since we included two undesirable outputs. By solving the following equations, we can estimate the GUEIW and its two decompositions ECEIW and ENEIW [51]. The estimated DMU is valid in industrial water when the value of the GUEIW is equal to 1 and is ineffective when the GUEIW is less than 1. ECEIW and ENEIW are the same case.

$$
\begin{gathered}
\text { GUEIW }=\frac{\left(1-\beta_{I W}\right)+\left(1-\beta_{Y}\right) \frac{1}{2}\left[\left(1-\beta_{W W}\right)+\left(1-\beta_{O P}\right)\right]}{3}=1-\frac{\beta_{I W}+\beta_{Y}+\frac{1}{2}\left(\beta_{W W}+\beta_{O P}\right)}{3} \\
E C E I W=\frac{\left(1-\beta_{I W}\right)+\left(1-\beta_{Y}\right)}{2}=1-\frac{\beta_{I W}+\beta_{Y}}{2}
\end{gathered}
$$




$$
E N E I W=\frac{\left(1-\beta_{I W}\right)+\frac{1}{2}\left[\left(1-\beta_{W W}\right)+\left(1-\beta_{O P}\right)\right]}{2}=1-\frac{\beta_{I W}+\frac{1}{2}\left(\beta_{W W}+\beta_{O P}\right)}{2}
$$

\section{Empirical Results}

In this section, we present the data including the inputs and outputs of the GNDDF framework. We collected annual industry data for all 16 Korean local government levels from 2006-2015. In this chapter, we calculated GUEIW based on the non-radial directional distance function (NDDF) and GNDDF models for comparison. In order to examine the main catalyst for GUEIW growth in Korea, we calculated the two forms of decomposition of the GUEIW: ECEIW and ENEIW.

\subsection{Data Collection}

In the DEA model, production inputs include two basic types: Industrial labor (L) and industrial capital (K); we added industrial water (IW) as the third input. We selected industrial GDP as the desirable output and selected water waste (WW) and organic pollutants (OP) \{Organic pollutant $(\mathrm{kg} /$ year $)=$ BOD $(\mathrm{mg} / \mathrm{l}) \times$ water waste $\left(\mathrm{m}^{3} /\right.$ year $\left.) \times 10^{3}\right\}$ as two undesirable outputs. Table 2 shows the descriptive statistics for each variable. The data were derived from the Korean Statistical Information Service (KOSIS). The industrial GDP and capital were converted based on 2010 prices.

Table 2. Descriptive statistics for variables.

\begin{tabular}{cccccccc}
\hline \multirow{2}{*}{ Input } & Variable & Unit & Mean & $\begin{array}{c}\text { Std. } \\
\text { Dev. }\end{array}$ & Min & Max & Obs. \\
\cline { 2 - 8 } & Labor & $10^{3}$ person & 166.43 & 183.20 & 3.14 & 885.85 & 160 \\
\cline { 2 - 8 } & Industrial water & $10^{7} \mathrm{~m}^{3}$ & 11.16 & 10.91 & 1.68 & 43.90 & 160 \\
\cline { 2 - 8 } & Capital & $10^{12} \mathrm{KRW}$ & 6.11 & 14.82 & 0.02 & 82.88 & 160 \\
\hline \multirow{2}{*}{ Desirable output } & GDP & $10^{12} \mathrm{KRW}$ & 172.09 & 157.39 & 11.02 & 753.95 & 160 \\
\hline \multirow{2}{*}{ Undesirable output } & water waste & $10^{6} \mathrm{~m}^{3}$ & 11.90 & 10.54 & 0.29 & 46.87 & 160 \\
\cline { 2 - 8 } & Organic pollutant & $10^{3}$ ton & 5.63 & 4.81 & 0.19 & 20.98 & 160 \\
\hline
\end{tabular}

Sources: Korean Statistical Information Service (KOSIS) (http://kosis.kr/).

\subsection{Results and Discussion}

As demonstrated in Figure 4, the GUEIW calculated from the GNDDF model is always lower than the value based on the NDDF model during the study period, with average values of 0.929 and 0.864 . This indicates that the GUEIW based on the NDDF model might be over-estimated, as it is based on contemporary environmental production technology. The NDDF measures relative efficiency and its evaluation criteria are determined by the evaluated DMUs. The efficiency scores obtained under different evaluation criteria are not comparable. To compare efficiency intertemporally, they must be carried out on the same benchmark (frontier). For example, when evaluating the efficiency of 16 local governments in 2006, relevant data constituted a frontier surface A, and the efficiency of each DMU was relative to the evaluation benchmark $A$. When evaluating the efficiency of 16 local governments in 2007, relevant data constituted a new frontier surface B, and the efficiency of each DMU was relative to the evaluation benchmark B. Generally, A and B are not the same, so the efficiency values in 2006 and 2007 were not comparable. If intertemporal comparisons are to be made, the efficiency of the two years must be based on the same frontier. The GNDDF in this paper refers to the data of the same region sampled in the ten years from 2006 to 2015 as different DMUs. The 160-sample data are then combined to create a common frontier on which the efficiency may be measured. However, the GNDDF model encompasses all concurrent technologies during the sample period. The calculated value is more reasonable because the most efficient node 1 is based on global environmental production technology. Therefore, the following analysis was based on the GNDDF model. In Figure 4, the GUEIW trend 
on GNDDF exhibits an m-shaped curve, which can be divided into three phases. The first phase is 2006-2007, the second 2008-2012, and the third 2013-2015. The first phase shows a rising trend from 2006-2007, indicating that industrial water use efficiency had achieved obvious improvement during the two years, but decreased in 2008 because of the global economic crisis. A rising trend can be seen again after 2010, following strong support for President Lee's "green growth policies." However, this upward trend only lasted two years; in 2013, a sharp decline occurred again following less emphasis on the environment by President Park's administration. It is clear that the GUEIW for Korea experienced two notable increase-decrease phases over the sample period. Measurements during 2007 and 2012 show that water use was more efficient; this may stem from the impacts of ENEIW and ECEIW. Therefore, in order to further understand the dynamic changes in GUEIW, it is necessary to analyze the trends of its contributing factors.

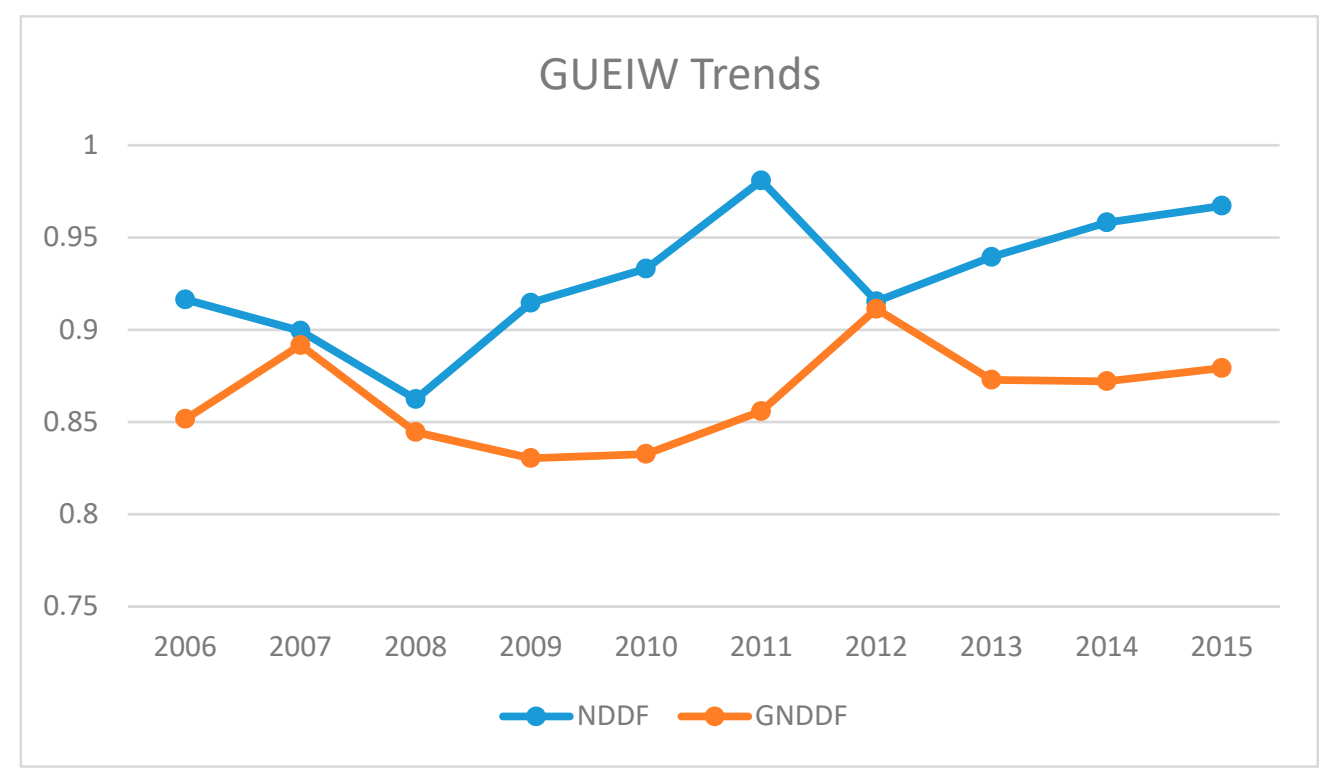

Figure 4. The green use efficiency of industrial water (GUEIW) for Korea based on the non-radial directional distance function (NDDF) and global non-radial directional distance function (GNDDF) models, 2006-2015.

Based on Equation (6) and as shown in Figure 5, we were able to outline the trends in ECEIW and ENEIW for Korea. It is clear that they exhibited similar trends as the GUEIW. There was no large gap during the study period, but the value of ECEIW was higher than that of ENEIW, with an average value of 0.870 , while that of ENEIW was 0.864 . This implies that environmental efforts may present some opportunity costs that are expressed in the gap between ECEIW and ENEIW. The year 2010 exhibited the biggest gap between ECEIW and ENEIW, with average values of 0.845 and 0.826 . This implies that the growth of GUEIW is mainly driven by ECEIW and that environmental issues function as constraints in the achievement of green use efficiency of industrial water in Korea. This is consistent with the argument of Wang et al. [51], who stated that environmental protection of industrial sectors needs to be improved in China too. In order to improve the economic efficiency of industrial water use, advanced water technology should be developed or introduced to make full use of water resources in industrial production. For example, in Denmark, through technology integration, "wastewater treatment plants" could be turned into "energy factories", biomass power could be produced by extraction of organic matter in sewage, and enough electricity could be supplied not only to run the motor, but also to pump water and have a surplus. In addition, waste water treatment plants use the money earned from waste power generation and heating to support the operation of the sewage treatment plant and even to achieve a break-even point [52]. In addition, it is noteworthy that ENEIW showed a significant upward trend during 2006-2007 and 2010-2012, indicating a significant environmental improvement in Korea. 
This can be attributed to a series of laws and regulations. As the River Basin Law was amended in 2007 under the Long-term Comprehensive Water Resources Plan, the Korean government worked to ensure a stable supply of water in the event of climate change. The Korean government implemented the river-oriented national land improvement project (four-river restoration project) and the new national land development paradigm (low-carbon green growth) [53]. Nevertheless, the unanticipated international financial crisis in 2008 had a significant negative impact on Korea's industrial exports, which caused many factories to close down and workers to lose their jobs, resulting in sharp decreases in both ECEIW and ENEIW. This forced the central government to introduce a series of economic stimulus plans, the components of which included expanding investment in small- and medium-sized industries to ensure industrial growth, thus boosting the recovery of the ECEIW [54]. Under the stimulus plan, some small- and medium-sized industries in Korea have overemphasized temporary doubts about the monitoring and implementation of environmental policies; they take chances on not being regulated, causing serious industrial pollution to many rivers. This is consistent with our findings. Figure 5 demonstrates the rapid upward trend of the ECEIW after 2008, as well as a large gap in the ENEIW in 2010. As Water Vision 2020 was revised for the second time in 2011 [55], both the ECEIW and ENEIW exhibit upward trends. The period between 2008-2012 exhibits these stricter environmental regulations that can stimulate technological innovation and improve production efficiency, leading to resource savings and environmentally friendly industrial production. This provides evidence for the Porter hypothesis [56]. Unfortunately, since 2013, President Park Geun-hye changed the paradigm from "green growth" to "creative economy." Environmental policies became passive and loose compared with those during Lee Myung-bak's administration. These changes led to the decline of the GUEIW.

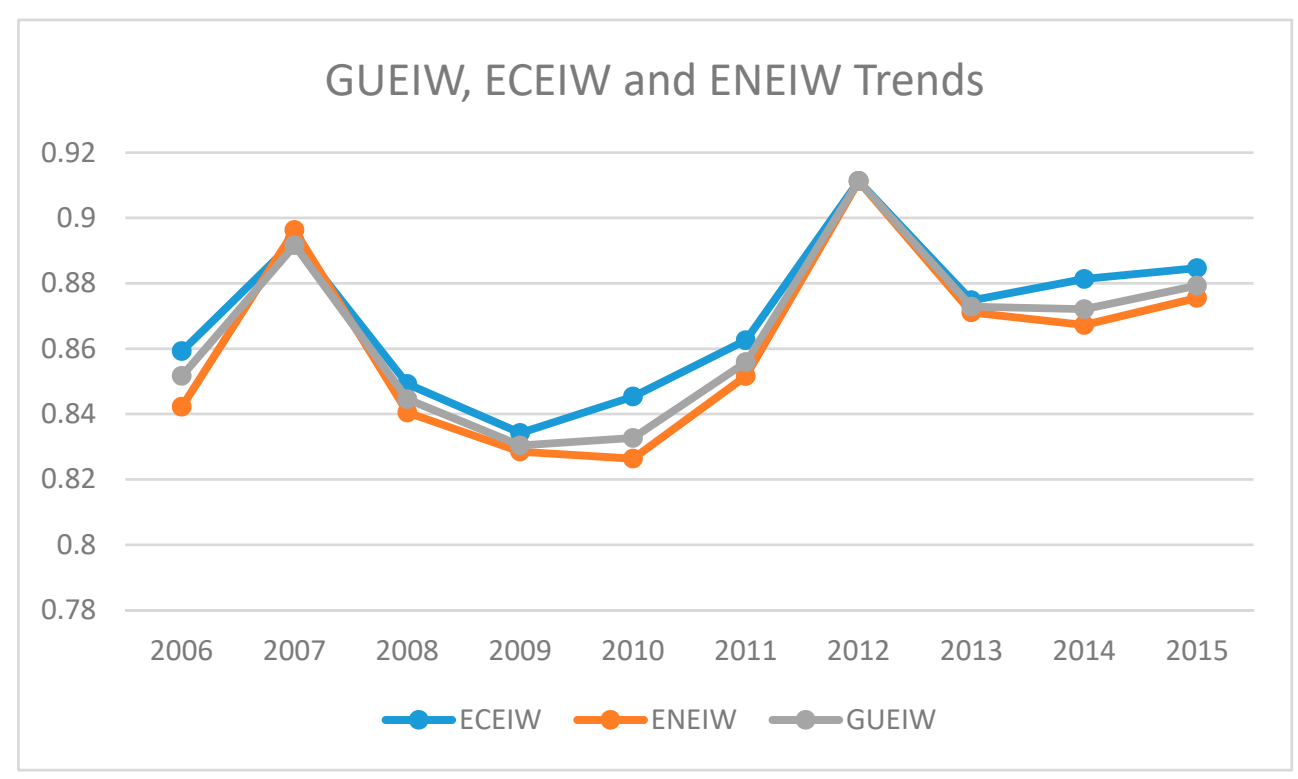

Figure 5. The GUEIW, economic efficiency of industrial water use (ECEIW), and environmental efficiency of industrial water use (ENEIW) for Korea, 2006-2015.

Figure 6 shows the average values of the GUEIW, ECEIW, and ENEIW at the local government levels. All three values are close to 1 in many governments; this is because Korea's water management system is centralized. In other words, all of these local governments share the same management experience and are under the same laws and regulations, so their efficiency values are extremely close. Therefore, there is no competition among local governments to enhance water management, resulting in similar performances. During the study period, Ulsan showed the highest value of 1 and Gangwon showed the lowest value of 0.351 . It is worth noting that 10 local governments with a GUEIW value of over 0.9 are located on the south and west coasts of South Korea (Chungnam, Busan, Jeonnam, Gyeonggi, Gyeongnam, Seoul, Gyeongbuk, Jeju, Gwangju, Ulsan). These local 
governments are situated downstream of rivers. Moreover, Gangwon, Daejeon, Daegu, Chungbuk, and Jeonnbuk are situated upstream, in the water source protection area. The results are not surprising, as the Han River Law was established in 1999 [57] to improve water quality, manage drinking water sources, and support the compensation of local governments in the upper reaches of the river basin as an economic incentive to reduce chemical use in factories and farms. In the same year, the River Basin Law envisaged the comprehensive improvement of national development plans [56]. This has led downstream industries to pay a kind of water environmental tax to upstream industries. Water users in downstream areas, such as Seoul, Gyeonggi, Chungnam, Busan, Jeonnam, Gwangju, Ulsan, and Gyeongnam pay for upstream water protection compensation in conservation areas that supply them with more environmentally friendly water. Gangwon, Chungbuk, Daejeon, Daegu, and Jeonnbuk provinces are the areas that protect upstream areas and their people by regulating economic activity (such as environmentally friendly housing and industries). It is worth mentioning that Incheon, although in the downstream.

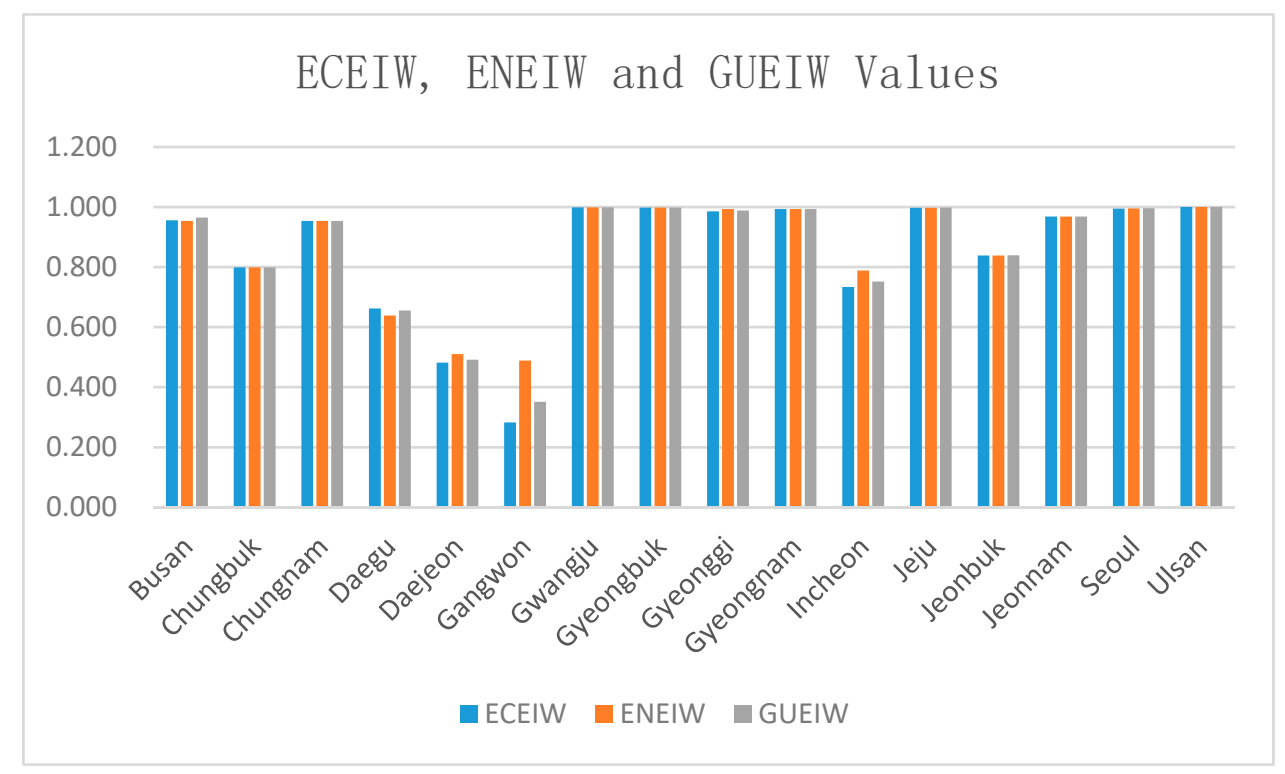

Figure 6. Average values of GUEIW, ECEIW, and ENEIW for Korea local governments.

$\mathrm{m}$ region, has a GUEIW value of 0.752 , lower than other downstream regions. This result is not surprising. Most of Incheon's cities have been developed as industrial zones for Seoul; thus, many of these zones, such as Namdong or Gajwa, consist of small- and medium-sized enterprises in the country. Compared with large enterprises in other cities such as Ulsan, industries in Incheon do not have sufficient technologies and facilities for environmentally friendly production processes, resulting in low ECEIW and ENEIW values. This situation also indicates that small- and medium-sized enterprises in the area can learn more from big companies by a spill-over effect.

Except for Incheon, all downstream regions outperformed the upstream region in all three indicators, particularly ECEIW. The government's efforts to ensure water quality inhibits industrial development in upstream areas, which negatively impacts the incomes of upstream areas; the relatively high water use costs in downstream areas encourage producers to save water. While the government focuses on compensating the upstream areas for water quality management with the water tax from downstream areas, such supplies cannot be sustainable because the government is only responsible for the initial stage of installation and does not provide any incentives for industries to reduce emissions. Regulations should be strengthened and effective incentives should be implemented to allow upstream industries to provide their own environmental protection activities. Therefore, the upstream region should focus on environmental protection as a valuable activity for sustainable performance and develop suitable industries with lower pollution and higher output. To develop 
such an industry, the water emission trading system (ETS) could be a good option for sustainable performance because the industry may reduce water use (quantitative efficiency) as well as produce less pollution (qualitative efficiency) for enhanced GUEIW. Here, ETS is the market-oriented carbon emission regulatory mechanism for the participating unit to reduce its carbon emission for better compensation in the ETS market. A water ETS could be constructed in a similar direction with caps and a trading system based on water management of industries.

\section{Conclusions}

Since water stress-which mainly comes from industrial water waste and water pollution-poses a significant threat to sustainable water management in Korea, it is urgent to assess GUEIW and make useful policy recommendations. Based on the GNDDF model, this paper calculated GUEIW in 16 Korean local governments from 2006 to 2015 based on two decomposition indicators: ECEIW and ENEIW.

Empirical results showed that GUEIW exhibited fluctuations during the study and that the growth of GUEIW was mainly driven by ECEIW. In order to improve the economic efficiency of industrial water use, advanced water technology should be developed or introduced to make full use of water resources in industrial production. Local governments should employ advanced technology and help less developed local governments achieve enhanced industrial water use.

For the ENEIW, environmental issues might be constraints for achieving green use of industrial water. Stricter environment regulations can stimulate technological innovation and improve water management efficiency, leading to water resource savings and environmentally friendly industrial production. This result supports the arguments related to the Porter hypothesis. It also demonstrates that environmental deregulation leads to a decline in GUEIW.

Regarding local government heterogeneity, the downstream region outperformed the upstream region in all three indicators, particularly in ECEIW. The government's efforts to ensure water quality inhibits industrial development in upstream areas. Upstream area incomes are much lower than in downstream areas, as downstream industries have to pay upstream industries for upstream water quality management. With relatively high water use costs, producers in downstream regions promote conservation of water. Upstream industries, however, may easily create water waste due to relatively low prices of water use. In order to improve the economic efficiency of industrial water use in upstream areas, an advanced water technology should be developed and introduced to make full use of water resources in industrial production. The local government in upstream regions should help local industries acquire advanced technology. In addition, the government can provide incentives for producers to save water to encourage industrial water saving. Water ETS could be one of the best alternatives for these performance-oriented policies.

Author Contributions: The authors are contributed each part of a paper by Conceptualization, Y.C.; Methodology, N.W.; Software, N.W.; Validation, Y.C.; Formal Analysis, N.W.; Investigation, Y.C.; Resources \& Data Curation, N.W.; Writing-Original Draft Preparation, N.W.; Writing—Review \& Editing, Y.C.; Visualization, N.W.; Supervision, Y.C.; Project Administration, Y.C.; Funding Acquisition, Y.C.

Funding: This research received no external funding.

Conflicts of Interest: The authors declare no conflict of interest.

\section{References}

1. Kim, B.W.; Kim, G.B.; Kim, D.G.; Koh, Y.K.; Choi, D.H. Current states of the Global water market and considerations for the Groundwater industry in South Korea. J. Eng. Geol. 2014, 24, 431-440. [CrossRef]

2. Baron, J.S.; Poff, N.L.; Angermeier, P.L.; Dahm, C.N.; Gleick, P.H.; Hairston, N.G.; Jackson, R.B.; Johnston, C.A.; Richter, B.D.; Steinman, A.D. Meeting ecological and socieal needs for freshwater. Ecol. Appl. 2002, 12, 1247-1260. [CrossRef]

3. Vugteveen, P.; Lenders, H.J. The duality of integrated water management: Science, policy or both? J. Integr. Environ. Sci. 2009, 6, 51-67. [CrossRef] 
4. Choi, I.-C.; Shin, H.-J.; Nguyen, T.T.; Tenhunen, J. Water Policy Reforms in South Korea: A Historical Review and Ongoing Challenges for Sustainable Water Governance and Management. Water 2017, 9, 717. [CrossRef]

5. Han, S.-Y.; Kwak, S.-J.; Yoo, S.-H. Valuing environmental impacts of large dam construction in Korea: An application of choice experiments. Environ. Impact Assess. Rev. 2008, 28, 256-266. [CrossRef]

6. Hoang, V.-N.; Seo, B.; Nguyen, T.T.; Hoang, V. Cost and environmental efficiency of rice farms in South Korea. Agric. Econ. 2012, 43, 369-378.

7. Organization for Economic Co-Operation and Development (OECD). Evaluation of Agricultural Policy Reforms in Korea; OECD Publishing: Paris, France, 2008.

8. Cho, C.J. The Korean growth-management programs: Issues, problems and possible reforms. Land Use Policy 2002, 19, 13-27. [CrossRef]

9. Kwak, S.J.; Russell, C.S. Contingent valuation in Korean environmental planning: A pilot application to the protection of drinking water quality in Seoul. Environ. Resour. Econ. 1994, 4, 511-526. [CrossRef]

10. Labadie, J.W.; Fontane, D.G.; Lee, J.H.; Ko, I.W. Decision support system for adaptive river basin management: Application to the Geum River basin, Korea. Water Int. 2007, 32, 397-415. [CrossRef]

11. Xi, D.L.; Sun, Y.S. Environmental Monitoring, 4th ed.; Higher Education Press: Beijing, China, 2010; Volume 7, pp. 127-135.

12. Water Resources Management Information System. Available online: http://www.wamis.go.kr/wke/wke_ wqbase_lst.aspx\#menu02 (accessed on 1 July 2019).

13. Kim, K.M. Improvement of the Han River Watershed Management Fund Policies; National Assembly Research Service (NARS) Issue Report 160; NARS: Seoul, Korea, 2012.

14. Shin, H.J.; Jeon, C.H.; Choi, I.C.; Yeon, I.C. Estimation of beneficiary's willingness to pay in mid and down-stream area to the water quality improvements in upper Bukhan River Basin. Seoul Stud. 2009, 10, 91-106. (In Korean)

15. Kumbhakar, S.C.; Bhattacharyya, A. Price distortions and resource-use efficiency in indian agriculture: A restricted profit function approach: A restricted profit function approach. Rev. Econ. Stat. 1992, 74, 231-239. [CrossRef]

16. Li, J.; Ma, X. The utilization efficiency of industrial water under the dual constraints of resource and environment-An empirical study based on sbm-undesirable and meta-frontier model. J. Nat. Resour. 2014, 29, 920-933. (In Chinese)

17. Cheng, H.; Hu, Y.; Zhao, J. Meeting China's water shortage crisis: Current practices and challenges. Environ. Sci. Technol. 2009, 43, 240-244. [CrossRef] [PubMed]

18. Xie, H.; Wang, W. Spatiotemporal differences and convergence of urban industrial land use efficiency for China's major economic zones. J. Geogr. Sci. 2015, 25, 1183-1198. [CrossRef]

19. Cai, Y.; Yue, W.; Xu, L.; Yang, Z.; Rong, Q. Sustainable urban water resources management considering life-cycle environmental impacts of water utilization under uncertainty. Resour. Conserv. Recycl. 2016, 108, 21-40. [CrossRef]

20. Gao, H.; Wei, T.; Lou, I.; Yang, Z.; Shen, Z.; Li, Y. Water saving effect on integrated water resource management. Resour. Conserv. Recycl. 2014, 93, 50-58. [CrossRef]

21. Liu, J.; Li, Y.P.; Huang, G.H.; Zeng, X.T. A dual-interval fixed-mix stochastic programming method for water resources management under uncertainty. Resour. Conserv. Recycl. 2014, 88, 50-66. [CrossRef]

22. Hu, Z.; Chen, Y.; Yao, L.; Wei, C.; Li, C. Optimal allocation of regional water resources: From a perspective of equity-efficiency. Resour. Conserv. Recycl. 2016, 109, 102-113. [CrossRef]

23. Tu, Y.; Zhou, X.; Gang, J.; Liechty, M.; Xu, J.; Lev, B. Administrative and market-based allocation mechanism for regional water resources. Resour. Conserv. Recycl. 2015, 95, 156-173. [CrossRef]

24. Zhang, N.; Xie, H. Toward green IT: Modeling sustainable production characteristics for Chinese electronic information industry, 1980-2012. Technol. Forecast. Soc. Chang. 2015, 96, 62-70. [CrossRef]

25. Shao, Y. Analysis of energy savings potential of China's nonferrous metals industry. Resour. Conserv. Recycl. 2016. [CrossRef]

26. Wu, H.; Shi, Y.; Xia, Q.; Zhu, W. Effectiveness of the policy of circular economy in China: A DEA-based analysis for the period of 11th five-year-plan. Resour. Conserv. Recycl. 2014, 83, 163-175. [CrossRef]

27. Bian, Y.; Yan, S.; Xu, H. Efficiency evaluation for regional urban water use and wastewater decontamination systems in China: A DEA approach. Resour. Conserv. Recycl. 2014, 83, 15-23. [CrossRef] 
28. Geissler, B.; Mew, M.C.; Weber, O.; Steiner, G. Efficiency performance of the world's leading corporations in phosphate rock mining. Resour. Conserv. Recycl. 2015, 105, 246-258. [CrossRef]

29. Jaeger, S.D.; Rogge, N. Cost-efficiency in packaging waste management: The case of Belgium. Resour. Conserv. Recycl. 2014, 85, 106-115. [CrossRef]

30. Charnes, A.; Cooper, W.W.; Rhodes, E. Measuring the efficiency of decision making units. Eur. J. Oper. Res. 1978, 2, 429-444. [CrossRef]

31. Ren, J.; Manzardo, A.; Mazzi, A.; Fedele, A.; Scipioni, A. Emergy analysis and sustainability efficiency analysis of different crop-based biodiesel in life cycle perspective. Sci. World J. 2013, 1, 1-12. [CrossRef] [PubMed]

32. Zhang, N.; Choi, Y. A note on the evolution of directional distance function and its development in energy and environmental studies 1997-2013. Renew. Sustain. Energy Rev. 2014, 33, 50-59. [CrossRef]

33. Zhang, N.; Kong, F.; Kung, C.C. On modeling environmental production characteristics: A slacks-based measure for China's Poyang lake ecological economics zone. Comput. Econ. 2014, 46, 1-16. [CrossRef]

34. Zhang, N.; Kong, F.; Choi, Y. Measuring sustainability performance for China: A sequential generalized directional distance function approach. Econ. Model. 2014, 41, 392-397. [CrossRef]

35. Ren, J.; Tan, S.; Dong, L.; Mazzi, A.; Scipioni, A.; Sovacool, B.K. Determining the life cycle energy efficiency of six biofuel systems in China: A data envelopment analysis. Bioresour. Technol. 2014, 162, 1-7. [CrossRef] [PubMed]

36. Hu, J.; Wang, S.; Yeh, F. Total-factor water efficiency of regions in China. Resour. Policy 2006, 31, $217-230$. [CrossRef]

37. Liao, H.; Dong, Y. Utilization efficiency of water resources in 12 western provinces of china based on the DEA and Malmquist TFP index. Resour. Sci. 2011, 33, 273-279.

38. Zhao, X.; Chen, B.; Yang, Z.F. National water footprint in an input-output framework-A case study of China 2002. Ecol. Model. 2009, 220, 245-253. [CrossRef]

39. Manzardo, A.; Ren, J.; Piantella, A.; Mazzi, A.; Fedele, A.; Scipioni, A. Integration of water footprint accounting and costs for optimal chemical pulp supply mix in paper industry. J. Clean. Prod. 2014, 72, 167-173. [CrossRef]

40. Wang, W.; Xie, H.; Jiang, T.; Zhang, D.; Xie, X. Measuring the total-factor carbon emission performance of industrial land use in China based on the global directional distance function and non-radial luenberger productivity index. Sustainability 2016, 8, 336. [CrossRef]

41. Xie, H.; Wang, W.; Yang, Z.; Choi, Y. Measuring the sustainable performance of industrial land utilization in major industrial zones of China. Technol. Forecast. Soc. Chang. 2016. [CrossRef]

42. Zhou, P.; Poh, K.L.; Ang, B.W. A non-radial DEA approach to measuring environmental performance. Eur. J. Oper. Res. 2007, 178, 1-9. [CrossRef]

43. Min, K.J. The Role of the State and the Market in the Korean Water Sector: Strategic Decision Marking Approach for Good Governance. Ph.D. Thesis, University of Bath School of Management, Bath, UK, January 2011.

44. Ministry of Land, Infrastructure and Transportation of Korea (MOLIT); Korea Water Resources Corporation (K-Water). Water for the Future: Water and Sustainable Development; K-Water: Daejeon, Korea, 2015.

45. Chung, Y.H.; Färe, R.; Grosskopf, S. Productivity and undesirable outputs: A directional distance function approach. J. Environ. Manag. 1997, 51, 229-240. [CrossRef]

46. Zhang, N.; Wang, B.; Chen, Z. Carbon emission reductions and technology gaps in the world's factory, 1990-2012. Energy Policy 2016, 91, 28-37. [CrossRef]

47. Zhang, N.; Wang, B.; Liu, Z. Carbon emissions dynamics, efficiency gains, and technological innovation in China's industrial sectors. Energy 2016, 99, 10-19. [CrossRef]

48. Chang, T.P.; Hu, J.L. Total-factor energy productivity growth, technical progress, and efficiency change: An empirical study of China. Appl. Energy 2010, 87, 3262-3270. [CrossRef]

49. Färe, R.; Grosskopf, S. New Directions: Efficiency and Productivity; Springer: New York, NY, USA, 2005.

50. Pastor, J.T.; Lovell, C.A.K. A Global Malmquist Productivity index. Econ. Lett. 2005, 88, 266-271. [CrossRef]

51. Wang, W.; Xie, H.; Dong, X.; Zhang, N. Sustainable water use and water shadow price in China's urban industry. Resour. Conserv. Recycl. 2018, 128, 489-498. [CrossRef]

52. Ministry of Land, Infrastructure and Transportation of Korea (MOLIT). (2011-2020): Water Vision 2020. In The Long-Term Comprehensive Water Resource Plan (2011-2020): The Second Revised Water Vision 2020; MOLIT: Sejong, Korea, 2011. (In Korean) 
53. Ministry of Environment. Available online: http://eng.me.go.kr/ndg/web/main.do (accessed on 15 July 2019).

54. Song, P.; Zhu, M. Korean economy in two economic crises and its countermeasures. Shangdong Soc. Sci. 2011, 191, 7. (In Chinese)

55. Oh, B.H. 2012 Modularization of Korea's Development Experience: Korea's River Basin Management Policy; Korea Development Institute School of Public Policy and Management: Seoul, Korea, 2013.

56. Porter, M.E.; van der Linde, C. Toward a new conception of the environment: Competitiveness relationship. J. Econ. Perspect. 1995, 9, 97-118. [CrossRef]

57. Choi, J.; Hearne, R.; Lee, K.; Roberts, D. The relation between water pollution and economic growth using the environmental Kuznets curve: A case study in South Korea. Water Int. 2015, 40, 499-512. [CrossRef]

(C) 2019 by the authors. Licensee MDPI, Basel, Switzerland. This article is an open access article distributed under the terms and conditions of the Creative Commons Attribution (CC BY) license (http://creativecommons.org/licenses/by/4.0/). 